\title{
Effect of extender supplementation with low-molecular-weight antioxidants on selected quality parameters of cryopreserved canine spermatozoa
}

\author{
Marek Lecewicz, Rafał Strzeżek, Władysław Kordan, Anna Majewska \\ Department of Animal Biochemistry and Biotechnology, \\ University of Warmia and Mazury, 10-718 Olsztyn, Poland \\ mlecew@uwm.edu.pl
}

Received: January 3, 2018 Accepted: June 12, 2018

\begin{abstract}
Introduction: The addition of low-molecular-weight antioxidants during the freezing process improves post-thaw sperm quality. The high antioxidant potential of cryopreserved semen could have a positive effect on the motility, viability, and energy status of sperm cells and their ability to bind to the zona pellucida of oocytes. The aim of the study was to determine the effects of different concentrations and combinations of vitamins $\mathrm{E}$ and $\mathrm{C}$ in a semen extender on selected quality parameters of frozenthawed canine spermatozoa. Material and Methods: The experimental material was the semen of four mixed-breed dogs. Sperm viability (motility, plasma membrane integrity, and mitochondrial function) was examined at 0,60 , and 120 min in semen samples supplemented with the extender and in the controls. Results: Combined supplementation with vitamins $\mathrm{C}+\mathrm{E}$ at a concentration of $200+200 \mu \mathrm{M} / 1 \times 10^{9}$ spermatozoa had the most profound effect on total sperm motility, linear motility, and the percentage of spermatozoa with intact plasma membrane and active mitochondria. Conclusion: The synergistic activity of vitamins $\mathrm{E}$ and $\mathrm{C}$ had a more beneficial influence on the quality of frozen-thawed sperm than these non-enzymatic antioxidants applied separately.
\end{abstract}

Keywords: canine sperm, cryopreservation, spermatozoa, antioxidants, viability.

\section{Introduction}

Innovative methods for the cryopreservation of canine semen facilitate the transfer of desirable genetic material from the most valuable stud dogs, contribute to the preservation of endangered canine breeds, and enhance the utilisation of specific genetic traits in male dogs (32). Recent research has contributed valuable information about the role of genes encoding behavioural and personality traits in dogs, including assistance dogs (22).

Cryopreservation influences sperm quality. Each step of the cryopreservation process, including dilution, chilling, freezing, and thawing, decreases the fertilising capability of sperm for artificial insemination (AI) (3, 26). The fertilising capability of mammalian sperm cells is determined mainly by the content of polyunsaturated fatty acids (PUFAs) which conditions their susceptibility to peroxidative damage (11).
Certain amounts of free radicals produced in the respiratory chain are required for normal sperm function. However, cryopreservation induces lipid peroxidation and increases the levels of reactive oxygen species (ROS), which disrupt the balance between free radicals and antioxidant system of frozenthawed spermatozoa, leading to oxidative stress (10). Prolonged exposure of spermatozoa to ROS compromises plasma membrane integrity causes a rapid loss of intracellular ATP and axonemal damage, decreases sperm motility, leads to the loss of intracellular enzymes and DNA fragmentation, impairs the fertilisation ability of sperm cells, and decreases pregnancy rates after IVF $(1,6,25)$.

ROS can be neutralised by antioxidant enzymes such as superoxide dismutase (SOD), glutathione peroxidase (GPX), and catalase (CAT). In sperm cells, the defence mechanism against lipid peroxidation also involves non-enzymatic molecules such as thioredoxin 
and glutathione, thiol-containing molecules, and vitamins E, C, and D (42). For human and several mammalian species sperm, the freezing medium has been supplemented with low-molecular-weight antioxidants to reduce oxidative stress $(16,17,23,28)$.

The aim of this study was to determine the effects of different concentrations and combinations of Trolox (water-soluble vitamin E) and L-ascorbic acid (vitamin C) in a semen extender on selected quality parameters of frozen-thawed canine semen.

\section{Material and Methods}

Semen collection. The experimental material was the semen from four mixed-breed dogs. Sperm-rich fractions of ejaculates were collected once weekly over a period of eight weeks. The dogs were housed in individual pens and fed commercial canine food. Water was available ad libitum.

During a preliminary assessment of the collected ejaculates, sperm motility was evaluated by the computer-aided sperm analysis (CASA) method and sperm cell concentrations were determined by the cytometric method in a haemocytometer. Semen samples with total motility higher than $80 \%$ and sperm counts higher than $200 \times 10^{6}$ sperm cells per $1 \mathrm{~cm}^{3}$ of semen were qualified for further analyses.

Freezing-thawing procedure. The procedure of cryopreservation was conducted according to Nizanski et al. (20) with some modifications (36). After preliminary assessment, the ejaculates were pooled and centrifuged $(700 \times \mathrm{g}, 5 \mathrm{~min})$. Seminal plasma was removed and semen sediments were diluted with standard Tris-citrate-fructose (TCF) extender (26) to a concentration of $2 \times 10^{8}$ spermatozoa $/ \mathrm{cm}^{3}$ and left to stand for $30 \mathrm{~min}$ at room temperature $\left(20^{\circ} \mathrm{C}\right)$. The samples were then cooled to $5^{\circ} \mathrm{C}$ for $60 \mathrm{~min}$. After chilling, the second dilution (1:1) was performed with an extender containing $5.0 \mathrm{~cm}^{3}$ of TCF, $4.0 \mathrm{~cm}^{3}$ of hen egg yolk, $0.8 \mathrm{~cm}^{3}$ of glycerol, and $0.2 \mathrm{~cm}^{3}$ of Orvus Es Paste (Equex STM, Minitube, Germany) to obtain a concentration of $1 \times 10^{8}$ spermatozoa $/ \mathrm{cm}^{3}$. The final concentrations of hen egg yolk, glycerol, and Orvus Es Paste in diluted semen samples were determined at $20 \%, 4 \%$, and $1 \%$, respectively. Equilibration time at $5^{\circ} \mathrm{C}$ was $15 \mathrm{~min}$. Then the semen was placed in $0.25 \mathrm{~cm}^{3}$ plastic straws (Minitube, Germany) and frozen in a closed expanded polystyrene box by placing filled straws on a rack suspended $4 \mathrm{~cm}$ above the surface of liquid nitrogen and allotting $10 \mathrm{~min}$ freezing time. Frozen straws and tubes were placed in a container with liquid nitrogen. Straws were thawed in a water bath at $70^{\circ} \mathrm{C}$ for $5 \mathrm{~s}(21)$.

Antioxidant treatment. During the second supplementation, the extender was enhanced with water-soluble vitamin E (Trolox, 6-Hydroxy-2,5,7,8tetramethylchromane-2-carboxylic acid, Sigma Chemical Co., USA) and vitamin C (Sigma Chemical
Co., USA). The following extender variants were used in the study: 1) extender without additives as the control sample; 2) extender with vitamin $\mathrm{E}$ at $400 \mu \mathrm{M} / 1 \times 10^{8}$ spermatozoa; 3) extender with vitamin $\mathrm{C}$ at $200 \mu \mathrm{M} / 1 \times 10^{8}$ spermatozoa; 4) extender with vitamins $\mathrm{C}+\mathrm{E}$ at $200+400 \mu \mathrm{M} / 1 \times 10^{8}$ spermatozoa; and 5) extender with vitamins $\mathrm{C}+\mathrm{E}$ at $200+200 \mu \mathrm{M} / 1$ $\times 10^{8}$ spermatozoa.

Post-thaw sperm viability (motility, plasma membrane integrity, and mitochondrial function) was examined at 0,60 , and $120 \mathrm{~min}$ in semen samples supplemented with the extender and in the controls.

Motility. Sperm motility was evaluated using the Hamilton-Thorne IVOS sperm analyser version 12.3 (Hamilton-Thorne Biosciences, USA). Software settings recommended by the manufacturer were used in analyses of canine sperm: 30 frames acquired, $60 \mathrm{~Hz}$ frame acquisition rate, 75 minimum cell contrast, 6 pixel minimum cell size, $75 \%$ straightness threshold, $100 \mu \mathrm{m} / \mathrm{s}$ path velocity threshold, $9.9 \mathrm{~m} / \mathrm{s}$ low average path velocity (VAP) cut-off, $20 \mu \mathrm{m} / \mathrm{s}$ low straight line velocity (VSL) cut-off, $0.80-4.93$ static size gates, 0.49-1.68 static intensity gates, and 22-84 static elongation gates. Total motility (\%) and progressive motility (\%) were determined in the IVOS analyser.

Plasma membrane integrity. Sperm plasma membrane integrity was assessed by dual fluorescent staining with SYBR-14 and propidium iodide (PI) (Live/Dead Sperm Viability Kit, Thermo Fisher Scientific, USA) according to the method described by Garner and Johnson (8) with minor modifications. Briefly, aliquots of sperm samples $\left(20 \times 10^{6}\right.$ spermatozoa $/ \mathrm{cm}^{3}$ ) were incubated with SYBR-14 (1 mM SYBR-14 in dimethyl sulphoxide (DMSO)) and PI solutions (2.4 $\mu \mathrm{M}$ PI in Tyrode's salt solution) for $10 \mathrm{~min}$ at $37^{\circ} \mathrm{C}$. After incubation, stained sperm cells were placed on microscopic slides and examined at $600 \times$ magnification under a fluorescence microscope (Olympus CH 30 RF-200, Japan). Sperm cells displaying only bright green fluorescence were regarded as viable spermatozoa with an undamaged plasma membrane. A minimum of 200 cells per slide were examined in random fields of each aliquot.

Evaluation of mitochondrial function by fluorescent microscopy. Sperm mitochondrial function was assessed by dual staining with the fluorescent probes 5,5',6,6'-tetrachloro-1,1',3,3'tetraethylbenzimidazolylcarbocyanine iodide, JC-1 (Molecular Probes, USA) and PI (Sigma Chemical Co., USA) according to previously described methods (9), with certain modifications (7). Aliquots of sperm samples $\left(20 \times 10^{6}\right.$ spermatozoa $\left./ \mathrm{cm}^{3}\right)$ were incubated with JC-1 solution (1 $\mathrm{mg} \mathrm{JC}-1 / \mathrm{cm}^{3}$ dimethyl sulphoxide, DMSO) for $15 \mathrm{~min}$ at $37^{\circ} \mathrm{C}$. After incubation, sperm samples were stained with PI (10 $\mu \mathrm{L}$ of PI solution in $0.5 \mathrm{mg} / \mathrm{cm}^{3}$ of phosphate buffer solution) for $10 \mathrm{~min}$ at $37^{\circ} \mathrm{C}$, washed $(5 \mathrm{~min}$ at room temperature), and sperm pellets were re-suspended in a HEPES buffer solution (10 mM 
HEPES, $0.85 \% \mathrm{NaCl}, 0.1 \%$ bovine serum albumin, $\mathrm{pH}$ 7.4).

Statistical analysis. Values were expressed as the mean \pm standard deviation (SD). The data were analysed by ANOVA, followed by the Duncan multiple comparison. Differences between means were considered significant at $\mathrm{P} \leq 0.05$.

\section{Results}

The effect of semen extender supplementation with different concentrations and combinations of vitamins $\mathrm{E}$ and $\mathrm{C}$ on the total motility of post-thaw semen with different incubation times is presented in Fig. 1.

Regardless of incubation time, a significantly higher percentage $(\mathrm{P} \leq 0.05)$ of frozen motile spermatozoa was preserved in the extender supplemented with vitamins $\mathrm{C}+\mathrm{E}\left(200+200 \mu \mathrm{M} / 1 \times 10^{9}\right.$ spermatozoa) than in the control. Similar results were observed after 60 and $120 \mathrm{~min}$ of incubation in semen cryopreserved with vitamins $\mathrm{C}$ and $\mathrm{E}$ (the latter in the higher concentration) $\left(200+400 \mu \mathrm{M} / 1 \times 10^{9}\right.$ spermatozoa). Rapidly thawed semen was characterised by a significantly higher percentage $(\mathrm{P} \leq 0.05)$ of total motile spermatozoa in samples supplemented with vitamin $\mathrm{C}$ at $200 \mu \mathrm{M} / 1 \times 10^{9}$ spermatozoa compared with the control.
A significantly higher $(\mathrm{P} \leq 0.05)$ percentage of spermatozoa exhibiting linear motility was observed in samples supplemented with vitamins $\mathrm{C}+\mathrm{E}$ at concentrations of $200+200 \mu \mathrm{M} / 1 \times 10^{9}$ spermatozoa and $200+400 \mu \mathrm{M} / 1 \times 10^{9}$ spermatozoa than in the controls (Fig. 2), also regardless of incubation time.

In an effect similarly undifferentiated by incubation time, the percentage of cryopreserved motile spermatozoa and sperm cells exhibiting linear motility was somewhat higher in samples supplemented with vitamin $\mathrm{E}$ at $400 \mu \mathrm{M} / 1 \times 10^{9}$ spermatozoa than in the controls (Figs 1 and 2); however, this difference was not statistically significant.

The effect of semen extender supplementation with different concentrations and combinations of vitamins $\mathrm{E}$ and $\mathrm{C}$ on the mitochondrial function and plasma membrane integrity of post-thaw semen with different incubation times is presented in Figs 3 and 4.

After 60 and $120 \mathrm{~min}$ incubation periods, the percentage of spermatozoa with active mitochondria and intact plasma membranes in post-thawed semen was significantly higher $(\mathrm{P}<0.05)$ in semen supplemented with vitamins $\mathrm{C}+\mathrm{E}\left(200+200 \mu \mathrm{M} / 1 \times 10^{9}\right.$ spermatozoa) than in the controls. Regardless of incubation time, supplementation with other concentrations of Trolox, vitamin C, or their combination did not exert a significant influence on the percentage of spermatozoa with active mitochondria and integral plasma membranes.

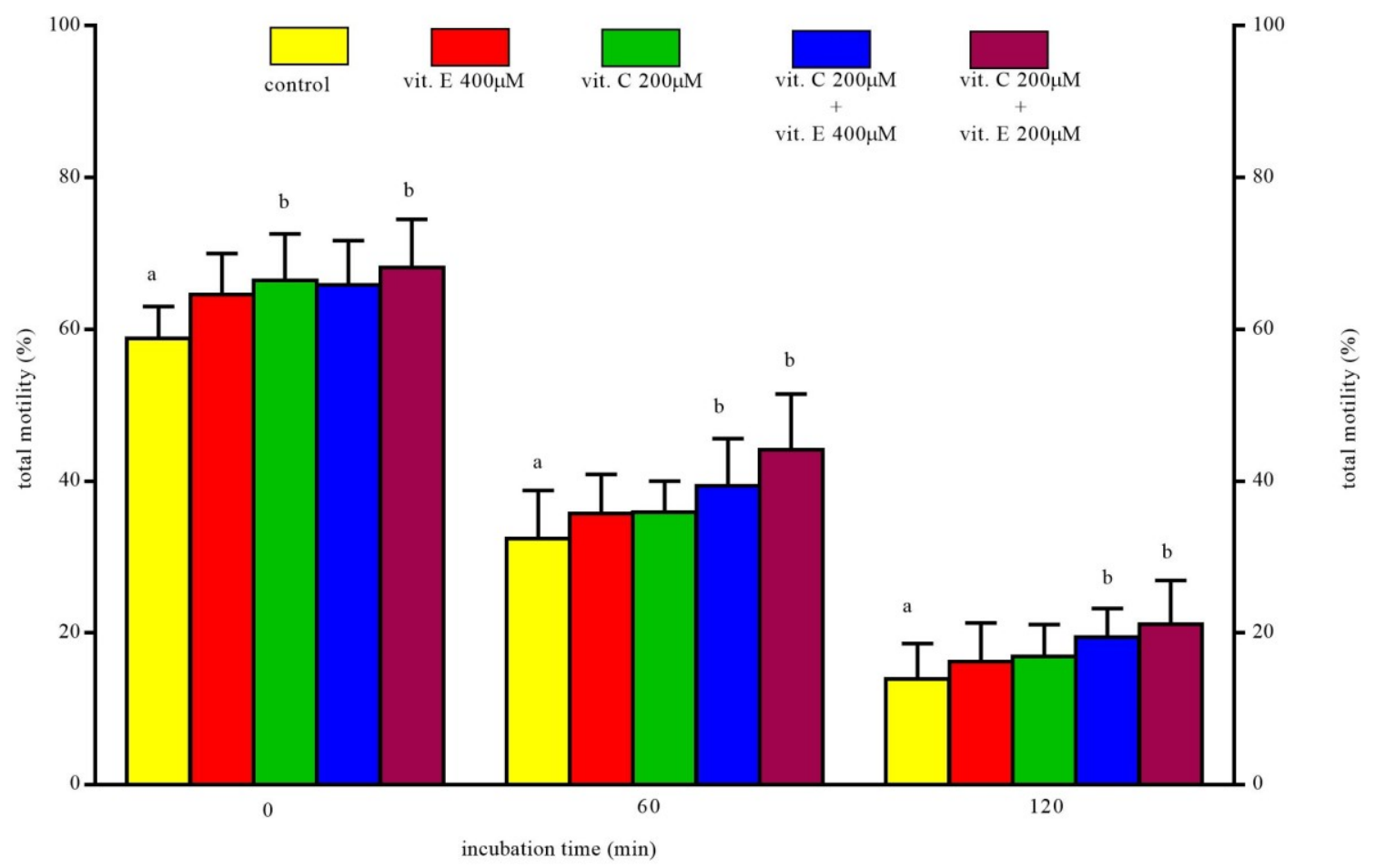

Fig. 1. The effect of semen extender supplementation with different concentrations and combinations of Trolox (water-soluble vitamin E) and L-ascorbic acid (vitamin C) on the total motility of frozen-thawed canine spermatozoa during $2 \mathrm{~h}$ of incubation. The presented values are means $\pm \mathrm{SD}$ for 20 ejaculates from four dogs. Values marked with different letters $(\mathrm{a}, \mathrm{b})$ differ significantly at $\mathrm{P} \leq 0.05$ 


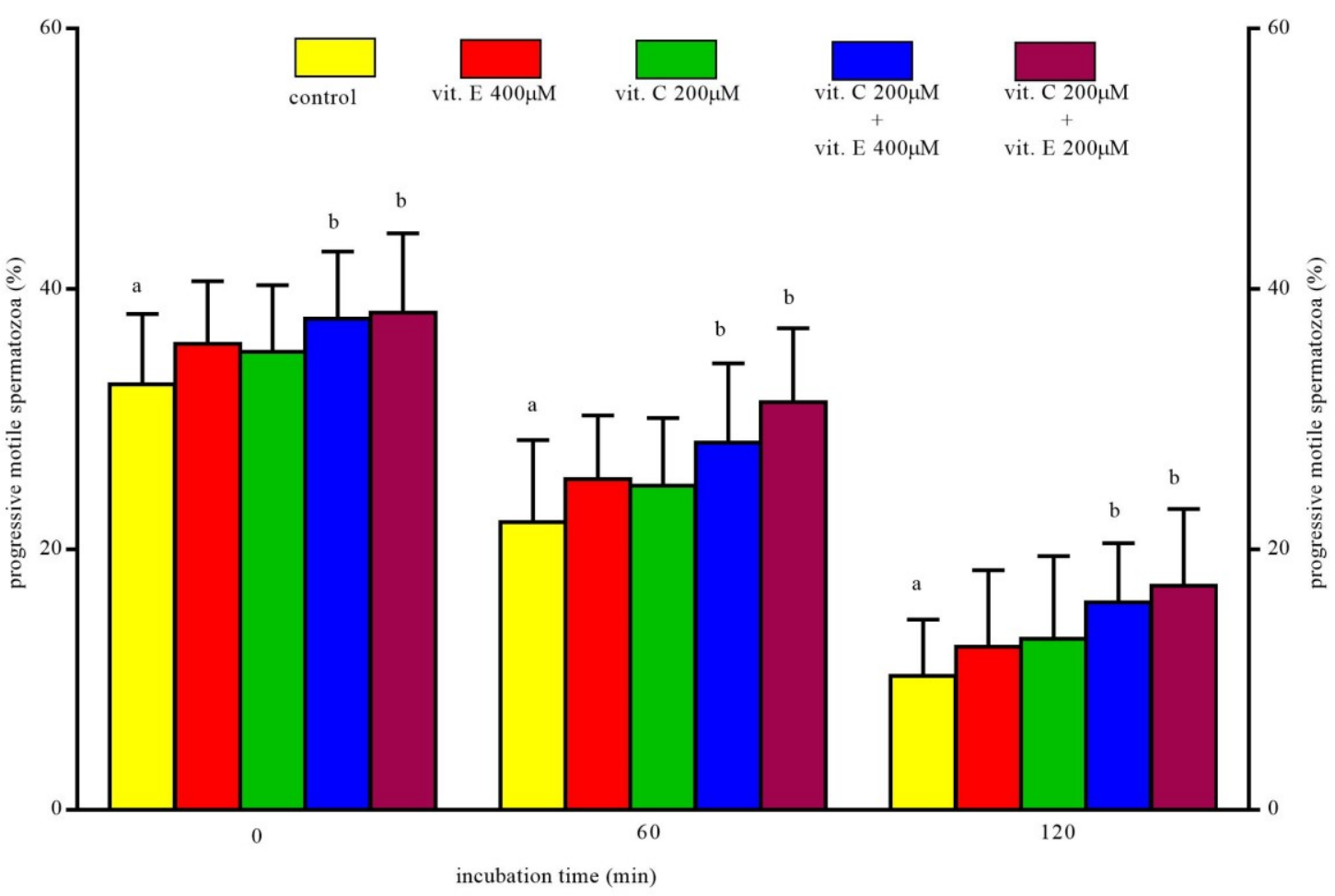

Fig. 2. The effect of semen extender supplementation with different concentrations of low-molecular-weight antioxidants on the progressive motility of frozen-thawed canine spermatozoa during $2 \mathrm{~h}$ of incubation. The presented values are means \pm SD for 16 ejaculates from four dogs. Values marked with different letters $(\mathrm{a}, \mathrm{b})$ differ significantly at $\mathrm{P} \leq 0.05$

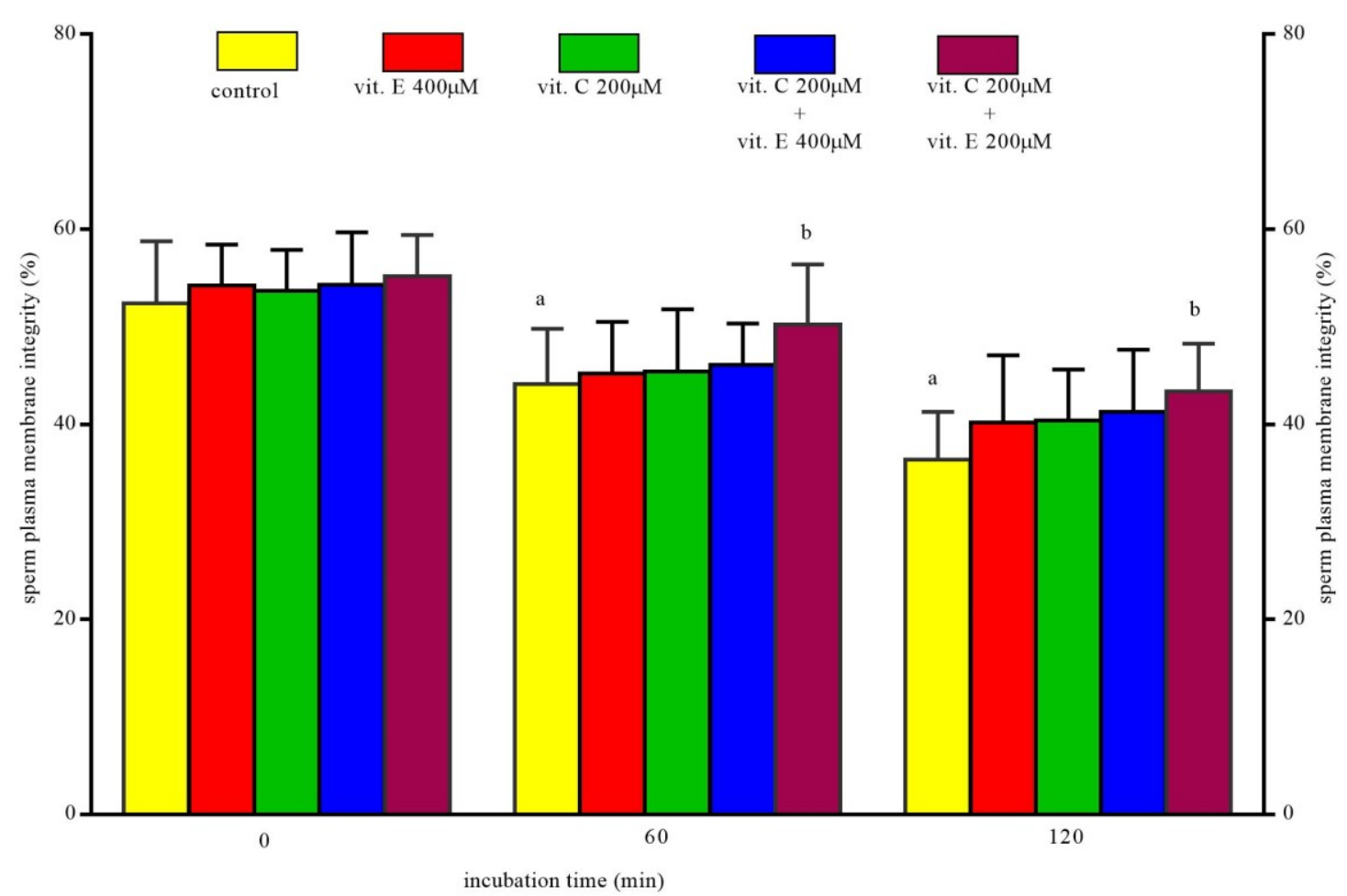

Fig. 3. The effect of semen extender supplementation with different concentrations of low-molecular-weight antioxidants on plasma membrane integrity in frozen-thawed canine spermatozoa during $2 \mathrm{~h}$ of incubation. The presented values are means \pm SD for 16 ejaculates from four dogs. Values marked with different letters $(a, b)$ differ significantly at $\mathrm{P} \leq 0.05$ 


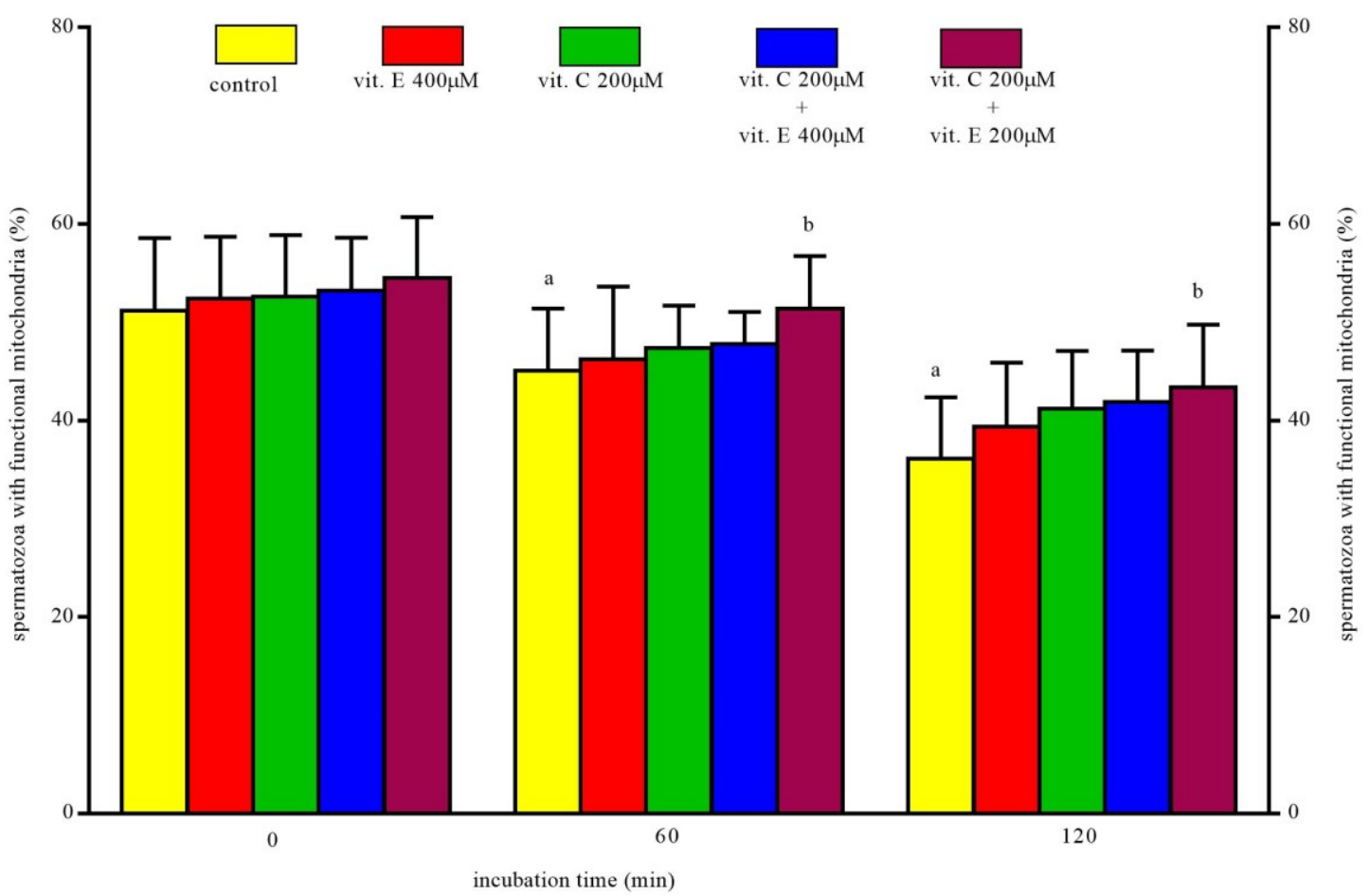

Fig. 4. The effect of semen extender supplementation with different concentrations of low-molecular-weight antioxidants on mitochondrial activity in frozen-thawed canine spermatozoa during $2 \mathrm{~h}$ of incubation. The presented values are means \pm SD for 16 ejaculates from four dogs. Values marked with different letters $(\mathrm{a}, \mathrm{b})$ differ significantly at $\mathrm{P} \leq 0.05$

\section{Discussion}

The balance between ROS generation and the activity of the antioxidant defence system containing both enzymatic and non-enzymatic components determines homeostasis in living organisms. Excessive ROS generation during cryopreservation compromises the quality of thawed spermatozoa (35). High antioxidant potential of cryopreserved semen could have a positive effect on the motility, viability, and energy status of sperm cells and their ability to bind to the zona pellucida of oocytes.

Vitamins $\mathrm{E}$ and $\mathrm{C}$ are natural antioxidants. The effect of semen extender supplementation with different concentrations and combinations of Trolox (water-soluble vitamin E) and L-ascorbic acid (vitamin C) on selected quality parameters of frozen-thawed canine spermatozoa was determined in this study.

Vitamin $\mathrm{E}$ is the primary component of the antioxidant system of sperm cells and one of the key compounds protecting plasma membranes against peroxidative damage (41). Vitamin $\mathrm{E}$ is soluble in lipids, and it could serve as the first line of defence against the peroxidation of polyunsaturated fatty acids on phospholipids with a membranous structure (5). Furthermore, vitamin E neutralises free radicals, protects the cell membrane against ROS, and enhances the functions of other antioxidants (12). Lipid peroxidation reactions are inhibited in membranes by eliminating peroxyl (ROO•), alkoxyl ( $\mathrm{RO} \bullet)$, and other free radicals which are generated during the conversion of lipid hydroperoxides in the peroxidative chain reaction $(3,25)$. Ascorbic acid is a water-soluble antioxidant that acts as a key cofactor in hydroxylation and amidation processes (13). Ascorbic acid and vitamin $\mathrm{E}$ are involved in the synthesis of collagen, proteoglycan, and components of the intercellular matrix $(33,12)$. The addition of vitamin $\mathrm{C}$ to extenders could improve sperm performance by minimising cell damage caused by radical scavenging (3).

In the present study, the addition of different concentrations of Trolox did not exert a significant influence on selected sperm parameters regardless of incubation time. However, Trolox-enhanced samples were characterised by a somewhat higher percentage of cryopreserved motile spermatozoa and sperm cells exhibiting linear motility without incubation time bearing upon this motility. A significant improvement of progressive motile sperm was shown in humans after the addition of vitamin $\mathrm{E}(40 \mu \mathrm{mol} / \mathrm{L})$ to the freezing medium (30). These results were similar to those of other studies. For example, Mohammed et al. (19) noted a significant improvement of progressive motile sperm and sperm viability after the addition of $40 \mu \mathrm{mol}$ of Trolox during the cryopreservation processes. On the other hand, Taylor et al. (37), found that vitamin E supplementation to semen cryopreservation medium at a concentration of $200 \mu \mathrm{mol}$ significantly improved semen post-thaw motility, but not vitality. Furthermore, in cryopreserved boar semen, vitamin $\mathrm{E}$ 
supplementation enhanced sperm motility, mitochondrial membrane potential, and membrane integrity in different ejaculate fractions $(23,24)$. Moreover, it was reported that addition of $\alpha$-tocopherol to fresh and stored boar semen samples significantly increased all kinematic parameters (15). Zeitoun and Al-Damegh (42) demonstrated that optimal post-thaw motility is achieved when vitamin E concentration in ram semen extender does not exceed $5 \mathrm{IU} / \mathrm{mL}$. In frozen ram semen, low concentrations of vitamin $\mathrm{E}$ also improved the quality of post-thaw sperm (2).

The concentrations of vitamin $\mathrm{E}$ applied in this study could be sub-optimal for preserving the viability of canine sperm cells, and the observed effects could differ with the concentration of the antioxidant supplement. In comparison with the control, the total percentage of motile spermatozoa cryopreserved with the addition of vitamin $\mathrm{C}\left(200 \mu \mathrm{M} / 1 \times 10^{9}\right.$ spermatozoa) was significantly higher only in rapidly thawed semen, which could be attributed to lower lipid peroxidation damage. Similar results were reported in other studies where extender supplementation with vitamin $\mathrm{C}$ increased the motility of spermatozoa in canine semen (40), bull semen $(27,33,34,35)$, and ram semen (4). Furthermore, Verma and Kanwar (39) showed a positive effect on human sperm motility of semen incubation with $800 \mathrm{mmol} / \mathrm{L}$ of ascorbic acid. However, paradoxically they found that higher doses of vitamin $\mathrm{C}(>1,000 \mathrm{mmol} / \mathrm{L})$ increased ROS levels, which decreased sperm motility.

Regardless of incubation time, the percentage of cryopreserved motile spermatozoa $(\mathrm{P} \leq 0.05)$ and the percentage of spermatozoa with active mitochondria and intact plasma membranes $(\mathrm{P} \leq 0.05)$ were significantly higher after 60 and $120 \mathrm{~min}$ incubation of post-thawed semen cryopreserved with the addition of vitamins $\mathrm{C}+\mathrm{E}\left(200+200 \mu \mathrm{M} / 1 \times 10^{9}\right.$ spermatozoa $)$. Similar results were noted in Mangalitsa boars where the combined addition of vitamins $\mathrm{E}$ and $\mathrm{C}$ had the most beneficial effect on the motility of frozen-thawed sperm (38). Mittal et al. (18) demonstrated that extender supplementation with vitamins $\mathrm{C}$ and $\mathrm{E}$ improved the motility, viability, and plasma membrane integrity of cryopreserved spermatozoa of Bhadawari bulls. In boars, extender supplementation with vitamins $\mathrm{E}$ and $\mathrm{C}$ together had more beneficial effect on the quality of frozen-thawed sperm than these nonenzymatic antioxidants when applied separately (14).

In conclusion, the results of this study indicate that total sperm motility, percentage of sperm cells exhibiting linear motion, and percentage of spermatozoa with intact plasma membranes and active mitochondria were higher when a supplemented extender for the cryopreservation of canine semen was improved with a combination of vitamins $\mathrm{C}+\mathrm{E}$ at a concentration of $200+200 \mu \mathrm{M} / 1 \times 10^{9}$ spermatozoa than with vitamins $\mathrm{E}$ and $\mathrm{C}$ separately.
Conflict of Interests Statement: The authors declare that there is no conflict of interests regarding the publication of this article.

Financial Disclosure Statement: This work was supported by the University of Warmia and Mazury in Olsztyn (No. 11.610.003-300).

Animal Rights Statement: The experiment was approved by the Local Ethics Committee at the University of Warmia and Mazury in Olsztyn.

\section{References}

1. Aitken R.J., Baker M.A.: Oxidative stress, sperm survival and fertility control. Mol Cell Endocrinol 2006, 250, 66-69.

2. Anghel A., Zamfirescu S., Coprean D., Sogorescu E.: The effects of cysteine, bovine serum albumin and vitamin $\mathrm{E}$ on the qualitative parameters of frozen-thawed ram semen. An Soc Natl Biol Cel 2009, 14, 97-103.

3. Asadpour R., Jafari R., Tayefi-Nasrabadi H.: Influence of added vitamin $\mathrm{C}$ and vitamin $\mathrm{E}$ on frozen-thawed bovine sperm cryopreserved in citrate and tris-based extenders. Vet Res Forum 2011, 1, 37-44.

4. Azawi O.I., Hussein E.K.: Effect of vitamins C or E supplementation to tris diluent on the semen quality of Awassi rams preserved at $5^{\circ} \mathrm{C}$. Vet Res Forum 2013, 4, 157-160.

5. Bansal A.K., Bilaspuri G.: Antioxidant effect of vitamin $\mathrm{E}$ on motility, viability, and lipid peroxidation of cattle spermatozoa under oxidative stress. Anim Sci Pap Rep 2009, 27, 5-14.

6. Chi H.J., Kim J.H., Ryu C.S., Lee J.Y., Park J.S., Chung D.Y., Choi S.Y., Kim M.H., Chun E.K., Roh S.I.: Protective effect of antioxidant supplementation in sperm-preparation medium against oxidative stress in human spermatozoa. Human Reprod 2008, 23, 1023-1028.

7. Dziekońska A., Fraser L., Strzeżek J.: Effect of different storage temperatures on the metabolic activity of spermatozoa following liquid storage. J Anim Feed Sci 2009, 18, 638-649.

8. Garner D.L., Johnson L.A.: Viability assessment of mammalian sperm using SYBR-14 and propidium iodide. Biol Reprod 1995, 553, 276-284

9. Garner D.L., Thomas C.A.: Organelle-specific probe JC-1 identifies membrane potential differences in the mitochondrial function of bovine sperm. Mol Reprod Dev 1999, 53, 222-229.

10. Guthrie H.D., Welch G.R.: Effects of reactive oxygen species on sperm function. Theriogenology 2012, 78, 1700-1708.

11. Hamedani A.M., Tahmasbi A.M., Naserian A.A., Ahangari Y.J.: Evaluation of vitamin E on microscopic parameters of chilled and frozen stored ram semen. Der Pharma Chemica 2016, 8, $16-22$.

12. Hosen M.B., Islam M.R., Begum F., Kabir Y., Howlader M.Z.H.: Oxidative stress induced sperm DNA damage, a possible reason for male infertility. Iran J Reprod Med 2015, 13, 525-532.

13. Huang D., Ou B., Prior R.L.: The chemistry behind antioxidant capacity assays. J Agric Food Chem 2005, 53, 1841-1856.

14. Izquiedo A.C., Iglesias Reyes A.E., Cervantes R.E., Guerra Liera J.E., Insunza Castro J.F., Villa Mancera A.E., Méndez Mendoza M., Huerta Crispín R., de Lourdes Juárez Mosqueda M., Gómez Vázquez A., Sánchez Aparicio P., Olivares Pérez J., Rodriguez Denis B.E., Peña Betancurt S.D.: Effect of addition of antioxidants in the freezing of boar semen on the motility and viability of sperm. Int J Curr Res 2017, 9, 47599-47600.

15. Jeong Y.J., Kim M.K., Song H.J., Kang E.J., Ock S.A., Kumar B.M., Balasubramanian S., Rho G.J.: Effect of alphatocopherol supplementation during boar semen cryopreservation on sperm characteristics and expression of apoptosis related genes. Cryobiology 2009, 58: 181-189. 
16. McCarthy M.J., Meyers S.A.: Antioxidant treatment in the absence of exogenous lipids and proteins protects rhesus macaque sperm from cryopreservation-induced cell membrane damage. Theriogenology 2011, 76, 168-176.

17. Michael A., Alexopoulos C., Pontiki E., Hadjipavlou-Litina D., Saratsis P., Boscos C.: Effect of antioxidant supplementation on semen quality and reactive oxygen species of frozen-thawed canine spermatozoa. Theriogenology 2007, 68, 204-212.

18. Mittal P.K, Anand M., Madan A.K., Yadav S., Kumar J.: Antioxidative capacity of vitamin E, vitamin C, and their combination in cryopreserved Bhadavari bull semen. Vet World 2014, 7, 1127-1131.

19. Mohammad B.M., Mohammad B., Saeid N., Abbas A., Nasrin T., Mohammad H.A., Azim H., Fardin A.: Effect of Trolox addition to cryopreservation media on human sperm motility. Iran J Reprod Med 2012, 10, 99-104.

20. Nizanski W., Dubiel A., Bielas W., Dejneka G.J.: Effects of three cryopreservation methods and two semen extenders on the quality of dog semen after thawing. J Reprod Fertil Suppl 2001, 57, 365-369.

21. Nöthling J.O., Shuttleworth R.: The effect of straw size, freezing rate, and thawing rate upon post-thaw quality of dog semen. Theriogenology 2005, 63, 1469-1480.

22. Ogata K., Sasaki A., Kato Y., Takeda A., Wakabayashi M., Sarentonglaga B., Yamaguchi M., Hara A., Fukumori R., Nagao Y.: Glutathione supplementation to semen extender improves the quality of frozen-thawed canine spermatozoa for transcervical insemination. J Reprod Dev 2015, 61, 116-122.

23. Peña F.J., Johannisson A., Wallgren M., Rodriguez Martinez H.: Antioxidant supplementation in vitro improves boar sperm motility and mitochondrial membrane potential after cryopreservation of different fractions of the ejaculate. Anim Reprod Sci 2003, 78, 85-98.

24. Peña F.J., Johannisson A., Wallgren M., Rodriguez Martinez H.: Antioxidant supplementation of boar spermatozoa from different fractions of the ejaculate improves cryopreservation: changes in sperm membrane lipid architecture. Zygote 2004, 12, 117-124.

25. Petruska P., Capcarova M., Sutovsky P.: Antioxidant supplementation and purification of semen for improved artificial insemination in livestock species. Turk J Vet Anim Sci 2014, 38, 643-652.

26. Pour H.A., Abdol-Mansour T., Abbas-Ali N.: The influence of vitamin $\mathrm{E}$ on semen characteristics of ghezel rams in during cooling and frozen process. Euro J Zool Res 2013, 2, 94-99.

27. Raina V.S., Gupta A.K., Raina K.S.: Effect of antioxidant fortification on preservability of buffalo semen. Asian-Australas J Anim Sci 2002, 15, 16-18.

28. Rossi M., Falomo M.E., Mantovani R.: Role of coenzyme Q and vitamin $\mathrm{E}$ on stallion semen motility evaluated both in frozen and cooled-stored semen Ital J Anim Sci 2016, 15, 595-603.
29. Rota A., Ström B., Linde-Forsberg C.: Effects of seminal plasma and three extenders on canine semen stored at 4 degrees C. Theriogenology 1995, 44, 885-900.

30. Sahib Yahya A.L.M.: Effect of the addition of vitamin E to sperm freezing medium on cryosurvival rate of sperm motility in asthenozoospermic patients. Int J Sci Res 2016, 6, 590-594.

31. Shen J., Deininger P., Hunt J.D., Zhao H.: 8-hydroxy-2'deoxyguanosine as a potential survival biomarker in patients with non-small cell lung cancer. Cancer 2007, 109, 574-580.

32. Silva A.R., de Cássia Soares Cardoso R., Uchoa D.C., Machado da Silva L.D.: Effect of tris-buffer, egg yolk, and glycerol on canine semen freezing. Vet J 2002, 164, 244-246.

33. Singh S.P., Virmani M., Malik R.K.: Effect of vitamin C on the seminal and biochemical parameters of Murrah buffalo bull semen during different stages of freezing. Haryana Vet 2015, 54, $15-18$.

34. Stolbov V.M., Rimanova L.D.: The effect of vitamins in the diluent on the quality of thawed bull semen. Anim Breed Abstr $1984,52,6546$

35. Stradaioli G., Noro T., Sylla L., Monaci M.: Decrease in glutathione (GSH) content in bovine sperm after cryopreservation: comparison between two extenders. Theriogenology 2007, 15, 1249-1255.

36. Strzezek R., Polakiewicz W., Kordan W.: The effect of two packaging systems on the post-thaw characteristics of canine sperm. Pol J Vet Sci 2015, 18, 249-253.

37. Taylor K., Roberts P., Sanders K., Burton P.: Effect of antioxidant supplementation of cryopreservation medium on post-thaw integrity of human spermatozoa. Reprod Biomed Online 2009, 18, 184-189.

38. Varo Ghiuru F., Ladoşi I., Roman I., Hettig A., Zăhan M, Miclea V.: Antioxidant medium for mangalita boar semen cryopreservation. Not Bot Horti Agrobo 2010, 67, 445-451.

39. Verma A., Kanwar K.C.: Effect of vitamin E on human sperm motility and lipid peroxidation in vitro. Asian J Androl 1999, 1, 151-154.

40. Wittayarat M., Kimura T., Kodama R., Namula Z., Chatdarong K., Techakumphu M., Sato Y., Mand T., Otoi T.: Long-term preservation of chilled canine semen using vitamin $\mathrm{C}$ in combination with green tea polyphenol. Cryo Letters 2012, 33, 318-326.

41. Yousef M.I., Abdallah G.A., Kamel K.I.: Effect of ascorbic acid and vitamin $\mathrm{E}$ supplementation on semen quality and biochemical parameters of male rabbits. Anim Reprod Sci 2003, 76, 99-111.

42. Zeitoun M.M., Al-Damegh M.A.: Effect of nonenzymatic antioxidants on sperm motility and survival relative to free radicals and antioxidant enzymes of chilled-stored ram semen. Open J Anim Sci 2015, 5, 50-58. 